Improved methods of epidemiological research will most likely reveal numerous curious and provocative associations between health experiences in early childhood and the occurrence of later disease. Reduced exposure to infection in childhood has been implicated as a factor in the pathogenesis of insulin dependent diabetes (IDDM). Caspar Gibbon et al put this theory to the test in a brief but important paper on pages $384-5$, which points to an association between decreased exposure to common infections in infancy, based on general practitioner records, and IDDM in children under the age of 16 years.

In conclusion, high quality epidemiological research during the next decade will present us with many intriguing discoveries about the influence of fetal and early childhood experience on diseases in adult life. We need also to tease out similarities of biological mechanisms of disease processes in the young and the elderly. Treatment strategies aimed at manipulating biological processes may be common to both. Stroke in the elderly and hypoxic-ischaemic brain damage in the newborn is but one example. We should also acknowledge the notion that "dependency" provokes similar psycho-social problems at the two extremes of life, including neglect and abuse. The basic science that governs the state of dependency of the very young and the elderly has similarities that might be exploited to provide improved preventive and management strategies for both, even though there will be differences in detail.

\title{
Is lifespan determined in utero?
}

\author{
A Aihie Sayer, C Cooper, D J P Barker
}

Low rates of growth in early life are now known to be associated with an increase in age related disease in later life. ${ }^{1}$ This is thought to reflect programming, the process whereby a stimulus or insult acting at a critical period of development in early life, has lasting or lifelong importance. ${ }^{2}$ In animal experiments that have examined the mechanisms responsible for programming, attention has focused on prenatal undernutrition and its influence on gene expression, cell division and differentiation, and tissue structure.

\section{Fetal growth and adult disease}

Epidemiological studies have shown that markers of poor fetal growth, including low early weight, thinness, and shortness at birth, are associated with increased mortality and morbidity from cardiovascular disease in later life. $^{13}$ Correlations have also been shown between poor early growth and the major cardiovascular risk factors-raised blood pressure,${ }^{4}$ raised plasma fibrinogen ${ }^{5}$ and serum cholesterol concentrations, ${ }^{6}$ impaired glucose tolerance $^{7}$ and reduced arterial compliance. ${ }^{8}$ These associations were first established by studies in Hertfordshire, where from 1911 to 1948 , every newborn baby was weighed and followed up to the age of 1 year. The prevalence of non-insulin diabetes and impaired glucose tolerance, for example, falls threefold between men who weighed 5.5 pounds at birth and those who weighed 9.5 pounds. ${ }^{7}$ These associations have been replicated in several different countries including the United States ${ }^{9}$ and India ${ }^{10}$ as well as in Britain. The associations are independent of adult lifestyle, and are not limited to cardiovascular disease. Chronic obstructive pulmonary disease ${ }^{11}$ and reduced bone mineral content ${ }^{12}{ }^{13}$ are both associated with reduced growth in utero and during infancy. The major determinant of fetal growth is nutrition ${ }^{14-16}$ and the fetal origins hypothesis proposes that fetal undernutrition programmes the long term adverse sequelae of small size at birth. Cardiovascular disease, impaired glucose tolerance, chronic obstructive lung disease and bone loss are age related disorders, but the link between fetal nutrition and aging has scarcely been explored.

\section{Postweaning and diet restriction studies} Nutrition is known to affect aging. The prolongation of lifespan by postweaning diet restriction was first shown in rodents in $1917^{17}{ }^{18}$ and the results have been replicated in many species, most recently primates. ${ }^{19}$ Several dietary manipulations with varying reductions in calorie and protein intake have been found effective. ${ }^{20}$ One study considered racial differences in renal and hepatic aging between Japanese and Caucasian people. Increased changes were seen in the Japanese histological specimens. It was suggested that the relatively low protein diet eaten by the Japanese was responsible for retarded development and accelerated aging. ${ }^{20}$ There has been just one controlled diet restriction study in humans. ${ }^{21}$ Healthy subjects over 65 years of age, living in a religious institution for the aged, were given their usual diet containing 2300 calories on odd days and 1000 calories from milk and fruit on even days. Control subjects continued with the usual diet every day. The experimental subjects spent significantly less time in an infirmary than controls and six of them died compared with 
13 controls over three years of observation, although this difference was not significant.

In addition to prolonging median and maximum lifespan, nutritional interventions in animals delay aging processes and disorders and maintain function. The mechanisms remain unknown. ${ }^{22} 23$ Initial suggestions that the effects were mediated through reduced growth after weaning were reconsidered when diet restriction was shown to have similar effects even when initiated in adult life. Other proposed mechanisms include an alteration in metabolic rate, free radical production, and protein turnover, but there is little evidence to support any of these.

\section{Preweaning undernutrition and aging}

The extensive investigation of postweaning diet restriction has not been accompanied by an equivalent body of work determining the effect of the same intervention in fetal life and infancy. ${ }^{24}$ The few gerontological studies of this issue in animals suggest the opposite effect. An early study in mice showed that a change in diet shortly after birth, sufficient to slow growth, resulted in a reduced lifespan. ${ }^{25}$ Studies in rats showed that a reduction in maternal diet in pregnancy produced offspring with an earlier age related decline in haemoglobin ${ }^{26}$ and shorter lifespan. ${ }^{27}$ Reduced nutrition in prenatal and early postnatal life has resulted in increased serum concentrations of age related hepatic and renal enzymes, ${ }^{28}$ and in the 1970 s it was first proposed that very early diet restriction might be associated with accelerated aging in later life. ${ }^{29}$ This notion was not widely accepted in gerontological research of the time, however.

Recent studies have investigated the effects of maternal undernutrition on a range of physiological variables in the offspring. Low protein in the diet of pregnant rats results in offspring with permanently raised blood pressure. ${ }^{30}$ It also reduces pancreatic $\beta$ cell mass and profoundly reduces islet vascularisation. ${ }^{31} \mathrm{~A}$ similar diet given for only three weeks after weaning permanently impairs the insulin response to glucose..$^{32}$ The evidence from animal studies is therefore that nutrition has profound effects on lifespan and age related structural and functional changes. Diet restriction seems to have the opposite effects when operating in either fetal and early postnatal life or in later life. Undernutrition before weaning is associated with more rapid aging and decreased lifespan, while diet restriction in adult life is beneficial.

\section{Fetal growth and aging}

Previous studies in Hertfordshire have established that reduced growth in utero and during infancy is associated with an increase in age related disease, ${ }^{7}$ but we know little about associations with normal aging processes. A recent study in North Hertfordshire addressed this. ${ }^{33}$ Markers of aging in a number of different body systems, including the eye, ear, muscle and skin, were measured in a sample of men and women aged 64 to 74 years. Lower weight at 1 year was associated with increased lens opacity, worse hearing, reduced grip strength and thinner skin. These correlations were independent of social class. This study provides preliminary evidence that undernutrition and reduced growth in utero and during infancy leads to more rapid aging in certain systems.

\section{Theories of aging}

Aging theories can be divided into two main groups according to whether aging is viewed as genetically predetermined or as a cumulative response to events over time. Evidence for the role of genes in aging comes from the existence of species specific lifespans, ${ }^{34}$ limited heritability of lifespan ${ }^{35}$ and the human progeroid syndromes where a simple gene defect is associated with phenotypic changes similar to aging which occur much earlier in life. ${ }^{36}$ A further distinction can be made as to whether aging is considered to have evolved as a beneficial process in its own right (adaptive theories) or as a byproduct of other processes (nonadaptive theories). One of the oldest adaptive theories of aging suggests that evolutionary pressure for aging genes would come from aging contributing to the fitness of the species by removing reproductively inactive aged individuals. Such an argument is circular, however. If aging did not occur there would be no need to remove old individuals.

Non-adaptive theories propose that natural selection for the genes involved has occurred for reasons other than to cause aging. The disposable soma theory ${ }^{37}$ suggests that aging is a result of the accumulation of defects in macromolecules and that these occur because of limited capacity for somatic maintenance and repair. Mathematical modelling can be used to determine the optimal allocation of nutritional resources between reproduction and repair to maximise survival of the species. This will be influenced by the degree of environmental danger to which the species is exposed. For example, species experiencing high levels of environmental danger such as predation are better served by early and rapid reproduction. Optimal allocation defined in this way results in less investment in repair than that required for perfect maintenance, and aging is the result. This theory suggests that repair is central to aging.

There is now experimental evidence to support a role for DNA repair in aging. There is a correlation between lifespan and efficiency of overall genomic DNA repair systems. ${ }^{38}$ DNA repair is also less efficient in cells from aging individuals or senescent cultures. ${ }^{39}$ This research has led to the recent identification of the defective gene in Werner's syndrome, a premature aging condition. The gene product resembles helicase which is required for DNA repair. ${ }^{40}$

Repair of other long lived molecules may also be important. It has been suggested that aging is a result of acquired damage to all long lived macromolecules. For example, accumulated cross links may cause structural stabilisation and altered actions in intercellular structural proteins and collagen as well as DNA. ${ }^{41-43}$ 
Programming of repair processes

Failure of repair at the tissue level could be programmed. The relations of early growth and aging markers in the lens, cochlea, muscle and skin found in Hertfordshire may have occurred because these are all organs contain large proportions of long lived molecules or cells. The lens contains crystallins which once formed are never turned over. ${ }^{44}$ They are synthesised in the outer cortex of the lens and gradually move to the centre as new crystallins are formed around the outside of the lens throughout life. The centre of an adult lens, therefore, contains molecules formed in utero. The cochlea has long lived collagen molecules ${ }^{41}$ and hair cells which are not replaced. ${ }^{45}{ }^{46}$ Muscle and skin contain collagen and elastin which also have a very slow turnover. ${ }^{41}$ Tissues containing a high proportion of long lived molecules or cells are likely to require particularly good repair systems as turnover is limited or non-existent. We postulate that early undernutrition results in impaired development of molecular and cellular repair mechanisms which may affect all tissues, but which are most critical in later life in those containing a high proportion of long lived components.

There is now good evidence that fetal growth and aging are related. This may be due to nutritional programming of aging and a possible mechanism is the impaired development of repair systems. This work now needs to be taken forward. Molecular studies of DNA repair capacity are planned, using markers such as mutation rates of specific genes, telomere length and DNA strand breaks. This will allow the postulated association between early growth and DNA repair to be investigated. The effects of preweaning diet restriction on growth, aging, and lifespan can be explored more fully in further animal studies where experimental manipulation of early diet is possible. Finally, follow up of the North Hertfordshire cohort will allow the rate of aging and its relation to early growth to be determined.

1 Barker DJP. Fetal origins of coronary heart disease. BMF 1995;311:171-4.

2 Lucas A. Programming by early nutrition in man. In: Bock GR, Whelan J, eds. The childhood environment and adult disease. Ciba Foundation Symposium 156. Chichester: John Wiley, 1991:38-50.

3 Barker DJP, Winter PD, Osmond C, Margetts B. Simmonds SJ. Weight in infancy and death from ischaemic heart disease. Lancet 1989;ii:577-80.

4 Barker DJP, Osmond C, Golding J, Kuh D, Wadsworth MEJ. Growth in utero, blood pressure in childhood and adult life, and mortality from cardiovascular disease. $B M \mathcal{F}$ 1989;298:564-7.

5 Barker DJP, Meade TW, Fall CHD, et al. Relation of fetal and infant growth to plasma fibrinogen and factor Vll concentrations in adult life. BMF 1992;304:148-52.

6 Fall CHD, Barker DJP, Osmond C, Winter PD, Clark PMS, Hales CN. Relation of infant feeding to adult serum cholesterol concentration and death from ischaemic heart disease. BMF 1992;304:801-5.

7 Hales CN, Barker DJP, Clark PMS, et al. Fetal and infant growth and impaired glucose tolerance at age $64 . B M \mathcal{F}$ growth and impaired

8 Martyn CN, Barker DJP, Jesperson S, Greenwald S, Osmond C, Berry C. Growth in utero, adult blood pressure and arterial compliance. Heart 1995;73:116-21.

9 Rich-Edwards J, Stampfer M, Manson J, et al. Birthweight, breastfeeding and the risk of coronary heart disease in the Nurses' Health Study. Am F Epidemiol 1995;141:S78.

10 Stein CE, Fall CHD, Kumaran K, Osmond C, Cox V, Barker DJP. Fetal growth and coronary heart disease in South India. Lancet 1997;348:1269-73.

11 Barker DJP, Godfrey KM, Fall C, Osmond C, Winter PD, Shaheen SO. The relation of birthweight and childhood respiratory infection to adult lung function and death from chronic obstructive airways disease. BMF 1991;303:671-5.

12 Cooper C, Cawley M, Bhalla A, et al. Childhood growth, physical activity, and peak bone mass in women. $\mathcal{F}$ Bone Min Res 1995; 10:940-7.

13 Cooper C, Fall C, Egger P, Hobbs R, Eastell R, Barker D. Growth in infancy and bone mass in later life. Ann Rheum Dis 1997;56:17-21.

14 Mellanby E. Nutrition and child-bearing. Lancet 1933;ii: $1131-7$

15 Godfrey KM, Redman CWG, Barker DJP, Osmond C. The effect of maternal anaemia and iron deficiency on the ratio of fetal weight to placental weight. Br f Obstet Gynaecol 1991; 98:886-91.

16 Godfrey K, Robinson S. Barker DJP, Osmond C, Cox V. Maternal nutrition in early and late pregnancy in relation to placental and fetal growth. BMF 1996;312:410-14.

17 Osborne TB, Mendel LB, Ferry EL. The effect of retardation of growth upon the breeding period and duration of life of rats. Science 1917; XLV:294-5.

18 McCay CM, Crowell MF, Maynard LA. The effect of retarded growth upon the length of life span and upon the ultimate body size. F Nutr 1935;10:63-74.

19 Roth GS, Ingram DK, Lane MA. Slowing ageing by caloric restriction. Nat Med 1995;1:414-15.

20 Young VR. Diet as a modulator of aging and longevity. Fed Proc 1979; 38:1994-2000.

21 Vallejo EA. La dicta de hambre a dias alternos en la alimentación de los viejos. Rev Clin Exp 1957; 63:25

22 Merry BJ. Effect of dietary restriction on lifespan. Rev Clin Gerontol 1991;1:203-13.

23 Weindruch R, Walford RL. The retardation of aging and disease by dietary restriction. Springfield: Charles C Thomas, 1988

24 Aihie Sayer A, Cooper C. Undernutrition and aging. Gerontology 1997;43:203-50.

25 Brailsford Robertson T. Ray LA. On the growth of relatively long lived compared with that of relatively short lived animals. F Biol Chem 1920;42:71-7.

26 Kahn AJ. Embryogenic effect on post-natal changes in hemoglobin concentration with time. Growth 1968;32:1322.

27 Hales CN, Desai M, Ozanne SE, Crowther NJ. Fishing in the stream of diabetes: from measuring insulin to the control of fetal organogenesis. Biochem Soc Transact 1996;24:341-50.

28 Roeder LM. Effect of the level of nutrition on rates of cell proliferation and of RNA and protein synthesis in the rat. Nutr Rep Int 1973;7:271-88.

29 Roeder LM, Chow BF. Maternal undernutrition and its long-term effects on the offspring. Am f Clin Nutr 1972; 25:812-1

30 Langley SC, Jackson AA. Increased systolic blood pressure in adult rats induced by fetal exposure to maternal low protein diets. Clin Sci 1994; 86:217-22.

31 Snoeck A, Remacle C, Reusens B, Hoet JJ. Effect of a low protein diet during pregnancy on the fetal rat endocrine pancreas. Biol Neonate 1990;57:107-18.

32 Swenne I, Crace CJ, Milner RDG. Persistent impairment of insulin secretory response to glucose in adult rats after limited periods of protein-calorie malnutrition early in life. Diabetes 1987;36:454-8.

33 Aihie Sayer A, Rauf A, Evans JR, Wormald RPL, Cooper C, Barker DJP. Reduced growth before one year of age is Barker DJP. Reduced growth before one year of age is
associated with more rapid aging. Age and Ageing 1996;25 (Suppl 2):7.

34 Hayflick L. Prospects for human life extension by genetic manipulation. In: Danon D, Shock NW, Marois M, eds. Aging: A challenge to science and society. Volume 1 Biology. Oxford: Oxford University Press, 1981:162-79.

35 Gavrilov LA, Gavrilova NS. The biology of lifespan: A quantitative approach. Chur: Harwood Academic Publishers, 1991.

36 Goldstein S. Human genetic disorders that feature premature onset and accelerated progression of biological aging. In: Schneider EL, ed. The genetics of aging. New York: Plenum Press, 1978 .

37 Kirkwood TBL, Wolff SP. The biological basis of ageing. Age and Ageing 1995;24:167-71.

38 Hart RW, D'Ambrosio SM, Ng KJ. Longevity, stability and DNA repair. Mech Age Devel 1979; 9:202-23.

39 Bohr VA, Evans MK, Fornace AJ. DNA repair and its pathogenetic implications. Lab Invest 1989; 61:143-61.

40 Yu C, Oshima J, Fu Y, et al. Positional cloning of the Werner's syndrome gene. Science 1996; 272:258-62.

41 Sell D, Monnier VM. Aging of long-lived proteins: extra-cellular matrix (collagens, elastins, proteoglycans) ology Section 11 Aging. New York: Oxford University Press, 1995.

42 Verzar F. The ageing of connective tissue. Gerontologia 1957;1:363-78.

43 Sinex FM. Aging and the lability of irreplaceable molecules. f Gerontol 1957;12:190-8.

44 Harding J. Cataract biochemistry, epidemiology and pharmacology. London: Chapman and Hall, 1991.

45 Winick M, Rosso P. Brasel JA. Malnutrition and cellular growth in the brain: existence of critical periods. In: Lipids, malnutrition and the developing brain. New York: Associated Scientific Press, 1972:199-212.

46 National Institutes of Health. Consensus Development Conference: Noise and hearing loss. Bethesda, MD:NIH, 1990. 